\title{
Early results of treatment for congenital clubfoot using the Ponseti method
}

\author{
Lukasz Matuszewski • Leszek Gil · Jacek Karski
}

Received: 22 August 2011/Accepted: 24 August 2011/Published online: 10 September 2011

(C) The Author(s) 2011. This article is published with open access at Springerlink.com

\begin{abstract}
The purpose of this study was to evaluate the early results of the Ponseti method in reducing extensive corrective surgery rates for congenital idiopathic clubfoot in patients treated in Children's Orthopaedic Clinic and Rehabilitation Department Medical University of Lublin between the years 2007-2011. Thirty-five patients with 47 idiopathic clubfeet were followed prospectively while being managed with the Ponseti method. Clubfoot severity was graded with use of the Dimeglio system. The initial correction was achieved, and early results were measured by using Pirani scoring method.
\end{abstract}

Keywords Congenital clubfoot · Ponseti method · Pediatric orthopedics

\section{Introduction}

Feet provide the foundation for static support for body and dynamic support during walking or running. They also fulfill an important esthetic function [1]. Congenital clubfoot has been a recognized condition since ancient Egypt. Pharaohs Siptah and Tutankhamun had clubfoot. This condition was described by Hippocrates and the Aztecs [2].

Clubfoot is a congenital deformity that occurs in $1 / 10,000$ birth. It is more common in boys. The deformity includes four components: metatarsus adductus, cavus, hindfoot varus and equinus. Congenital clubfoot is a three-dimensional malformation with its center in talocalcaneonavicular

Ł. Matuszewski $(\bowtie) \cdot$ L. Gil · J. Karski

Children's Orthopaedic Clinic and Rehabilitation Department, Medical University of Lublin, Lublin, Poland

e-mail: lukasz.matuszewski@am.lublin.pl articulation. The axis of deformation is interosseous talocalcaneal ligament [3].

The cause of clubfoot has long been debated by the medical community. According to the Journal of Children's Orthopaedics, this condition has been studied since the 1800s. Some scientific investigators concluded that the condition was caused by malformed bones, abnormalities of muscle, joint or vascular lesions and/or abnormal ligaments and tendons. Another opinion is that congenital clubfoot results when external forces put the foot or the feet in a faulty position while the fetus is developing [4]. Nowadays, there are two main hypotheses that say that congenital clubfoot is caused by neurogenic disorders in neuromuscle balance or gene variations [5].

Any feet deformation should be corrected as early as possible to provide physiological function of proprioceptors that gives good balance and helps learning to walk. Treatment for clubfoot has evolved from a minimal surgery to a casting technique and then to extensive surgery. Within the years, the principles of surgical technique in treatment for congenital clubfoot were changed and modified many times. The most popular types of surgical procedures that are used in treatment for congenital clubfoot are listed below.

- Medial side incision (Evans, Dega, Turco)

- Two skin incisions-medial and lateral side (Carroll, Sotirow, Uglov)

- Circumferential (Cincinnati) (McKay, Crawford)

- Semi-Cincinnati

Ponseti described his method in late 1950s. His method is an innovative, conservative treatment for clubfoot involving a gentle manipulation of the child's foot and the application of toe-to-groin plaster casts that is followed by bracing and tenotomy. The procedure consists of manual 
redresions, started as early as possible, which corrects a longitudinal arc of the foot and an abduction of a forefoot. With this treatment, soft structures are stretched with weekly, gentle manipulations. A plaster cast is applied after each weekly session to retain the degree of correction obtained and to soften the ligaments. After 4-6 weeks of the treatment, when adduction and supination of the calcaneum bone is corrected, the tight Achilles tendon is cut in a minor procedure (tenotomy) to perform correction of the equinal deformation. The corrected foot is put in a holding cast for 3 weeks to allow the tendon to regenerate. Then, when the final cast is removed, a "foot abduction brace" a.k.a. the Denis-Brown's device is fitted. This device consists of a pair of shoes attached to an adjustable bar at a specific width and angle. Ponseti achieved successful results in more than $95 \%$ of cases [6].

\section{Aim of the paper}

The main objective of this paper is to present the early results of treatment congenital clubfoot by Ponseti method.

\section{Materials and methods}

The paper is based on data for 35 children-25 boys and 10 girls with 47 clubfeet treated during the period of 2007-2011. We monitored the deformation before each redresion and casting, and before and after the tenotomy. To evaluate the effects of treatment, we used Pirani's scale with its six main features concerning external edge, medial crease and "covering" of the head of the talus bone in the midfoot region and posterior crease, incorrective equinal deformation and empty heel in hindfoot region. According to Pirani's scale, a total score of 6 points represents a severe clubfoot with a score of 0 points representing a normal foot.

\section{Results}

All 35 patients were newborns with 7 of them suffering from bilateral deformation. According to BensachelDimeglio's classification, 40 feet represented stift type of deformation and most of the patients had a maximal or medium grade of equinal, varus and adduction deformation (Table 1).

We started treating the patients as early as possible. For 25 patients, redresions and casting treatment began in the first or second day of life. Clubfeet were corrected with manipulations every 5-7 days followed by plaster-cast applications. Usually, the duration of such redresions and
Table 1 Angular deformation before treatment-most of them were medium or maximal $\left(40^{\circ}-90^{\circ}\right)$

\begin{tabular}{lll}
\hline Result after tenotomy & Sagital plane & Passive dorsal flexion \\
\hline Maximal & $71^{\circ}-90^{\circ}$ & 25 \\
Median & $41^{\circ}-70^{\circ}$ & 17 \\
Minimal & Below $40^{\circ}$ & 5 \\
\hline
\end{tabular}

Table 2 Angular deformation for varus and adduction after redresions and casting treatment—during passive correction-we reached $0^{\circ}-5^{\circ}$ in all treated patients

\begin{tabular}{lll}
\hline Deformation & $\begin{array}{l}\text { Grade of varus } \\
\text { and adduction deformation }\end{array}$ & $\begin{array}{l}\text { Number } \\
\text { of feet }\end{array}$ \\
\hline Spontaneous correction & $15^{\circ}-20^{\circ}$ & 45 \\
Passive correction & $0^{\circ}-5^{\circ}$ & 45 \\
Full correction & $0^{\circ}$ & 2 \\
\hline
\end{tabular}

Table 3 Correction in sagittal plane and ability of passive dorsal flexion after tenotomy-we reached good results in $85 \%$ of treated feet

\begin{tabular}{llll}
\hline $\begin{array}{l}\text { Result after } \\
\text { tenotomy }\end{array}$ & $\begin{array}{l}\text { Sagital } \\
\text { plane }\end{array}$ & $\begin{array}{l}\text { Passive dorsal } \\
\text { flexion }\end{array}$ & $\begin{array}{l}\text { Number of feet } \\
(\%)\end{array}$ \\
\hline $\begin{array}{l}\text { Good } \\
\text { Satisfactory }\end{array}$ & $0^{\circ}$ & $5^{\circ}-10^{\circ}$ & 39 feet $(85 \%)$ \\
\hline
\end{tabular}

casting treatment was 5-8 weeks. More were sometimes needed in the most severe cases of clubfoot. Then, we measured the residual deformation for varus and adduction through passive correction (Table 2). For all treated patients, we accomplished satisfactory results.

When the correction of adduction and supination of the calcaneum bone was completed, the tenotomy of Achilles tendon was performed. This minor surgical procedure, conducted under a light sedation, was applied to 34 children out of the total number of 35 treated children. For one child, excellent results were achieved after redresions followed by bracing so that no surgery was required. The remaining patients underwent the tenotomy followed by a 3-week-long holding cast period that allowed the tendon to regenerate longer. In $85 \%$ of treated feet, we achieved sufficient correction in sagittal plane and ability of passive dorsal flexion (Table 3). For the final correction in all treated cases, we used TIBAX or CLUBAX device, which is a simple instrument to perform corrections in all three planes. Such orthosis helped to preserve the good results after surgery (Fig. 1). We observed a decrease in dorsal flexion only in four cases. However, those four children did not use that device strictly according to our recommendation.

During the analysis of our final results, we presented data after follow-up of all patients (median 21 months), together 
Fig. 1 TIBAX and CLUBAX orthosis
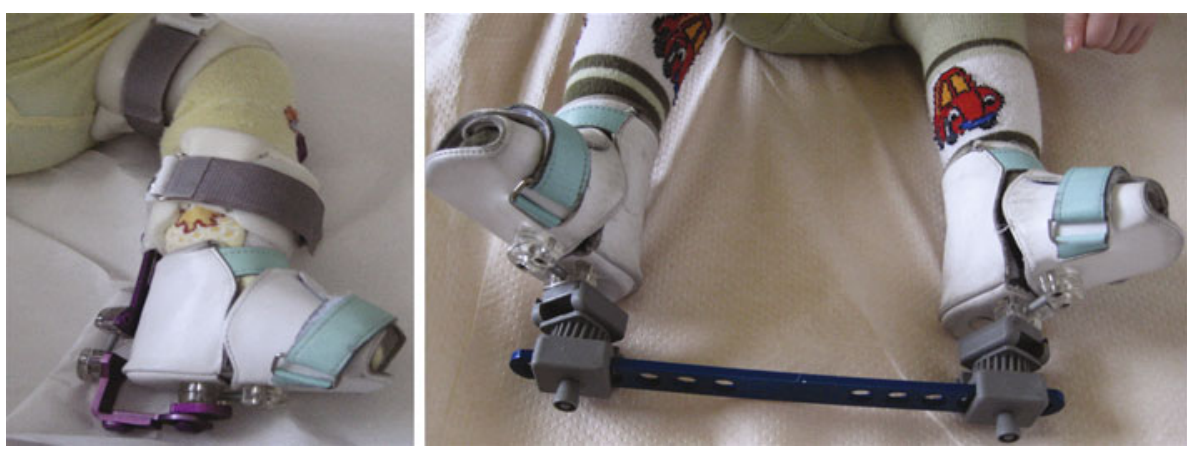

Table 4 Pirani scale before and after treatment-we accomplished $0.5-1.5$ point in all 33 treated feet

\begin{tabular}{lllll}
\hline $\begin{array}{l}\text { Before treatment by Ponseti } \\
\text { method }\end{array}$ & & \multicolumn{2}{l}{$\begin{array}{l}\text { 8-42 months after Achilles } \\
\text { tenotomy }\end{array}$} \\
\cline { 1 - 2 } \cline { 5 - 5 } Points & Number of feet & & Points & Number of feet \\
\hline 6 & 10 & & 1.5 & 9 \\
$5-5.5$ & 28 & & 1 & 16 \\
4.5 & 9 & 0.5 & 20 \\
\hline
\end{tabular}

with a subanalysis of patients according to Pirani's scale. It assessed the severity of clubfoot deformity and the response for treatment. The scores for all patients before the treatment ranged from 4.5 to 6 points. After the treatment, we accomplished a score of $0.5-1.5$ points in all 46 treated feet (Table 4). We evaluated the results of treatment as good or very good for $75 \%$ of patients. For the remaining patients, the results were evaluated as satisfactory.

\section{Discussion}

The main objective of treatment for congenital clubfoot is to obtain pain-free, plantigrade foot, with good mobility and without calluses. In general, children who suffer from such deformation undergo some type of surgery to complete the correction. This can range from a percutaneous heelcord lengthening to a wide release of medial, posterior and lateral structures, with or without transfer of the anterior tibial tendon [7, 8].

There is general agreement that initial treatment for congenital clubfoot should be nonsurgical. This leads Ponseti to develop his method in the 1950s, repopularized in the beginning of 2000 in the USA and Europe. Currently, manipulation, redresions and casting according to Ponseti method are the "gold standard," and this method is endorsed by the American Association of Orthopedic Surgeons. Napiontek [9] in 2004 introduced and widely popularized Ponseti method in Poland, and since 2007, we have been using it in our Clinic. Treatment should be initiated as soon as possible, preferably within the first week of life. The majority of clubfeet can be corrected in infancy in about 6-8 weeks with the proper gentle manipulations and plaster casts followed by tenotomy. However, the technique requires a lot of training, experience and practice [10].

In our study, nonoperative procedures took usually 5-8 weeks which is a similar period to Ponseti standards and that what other author report $[11,12]$. For the treatment performed at our clinic, tenotomy of the Achilles tendom was crucial for the completion of a successful correction of the foot. Despite successful initial treatment, congenital clubfoot has a natural tendency to recur. Therefore, bracing is essential and necessary to prevent a recurrence of deformation. There are several types of braces. All of them consist of a bar with shoes that are attached at the ends of the bar in external rotation. The device is worn $23 \mathrm{~h}$ a day for 3-4 months and then at nighttime for 2-4 years. In our clinic, we used TIBAX or CLUBAX device which was similar to orthosis recommended by POSNA (Pediatric Orthopaedic Society of North America) as: the Dobbs Dynamic Abduction Brace, the Markell or Mitchell Abduction Brace. Severity of the deformity at birth is not a reliable indicator of the odds for a relapse; therefore, almost all clubfoot patients are held to the same bracing protocols in order to provide them with the best protection against regression $[13,14]$. In early results, we noticed that all children who did not use the orthosis as it was prescribed experienced high recurrence rate. We have to add that in some severe cases, more invasive surgery treatment is needed to correct the position of the clubfoot despite using Ponseti method. Most often, a more invasive surgery is this is needed in cases when a child has other developmental problems as, e.g., arthrogryposis [15].

We also want to point out that the time when the child begins treatment by Ponseti method is an important factor. All of our patients received such treatment in first month of life. Most authors consider that a congenital clubfeet treatment has to start no more than a few months after birth. However, some resent researches showed that the Ponseti method is effective for children as old as ten, even in cases of a failed surgery [16, 17]. We agree with 
Ponseti's thesis that the basic of deformity in the congenital clubfoot is fibrosis of the soft tissue. Therefore, soft tissue in infants is more responsive to redresions, casting and finally bracing.

In essence, our study supports the principles of Ponseti's method, because in cases when these principles were strictly obeyed, all patients accomplished satisfactory results and there have been no recurrences that are known to us $[5,18]$. Therefore, we strongly recommend using this method to avoid more invasive surgery in the future. This method is of the particular value for the initial treatment of congenital clubfoot deformity.

Conflict of interest The authors of this manuscript have chosen not to furnish Ejost and its readers with information regarding any relationship that might exist between a commercial party and material contained in this manuscript that might represent a potential conflict of interest. No benefits in any form have been or will be received from a commercial party related directly or indirectly to the subject of this manuscript.

Open Access This article is distributed under the terms of the Creative Commons Attribution Noncommercial License which permits any noncommercial use, distribution, and reproduction in any medium, provided the original author(s) and source are credited.

\section{References}

1. Ostrowski J, Karski T, Matuszewski $Ł$ (2006) The role of the modified skin incision, the range of tendon lengthening and capsulotomy for the results of operative treatment of the congenital clubfoot. Pol J Environ Stud 15(6B):296-298

2. Cummings RJ, Davidson RS, Armstrong PF, Lehman WB (2002) Congenital clubfoot. Instr Course Lect 51:385-400

3. Dobbs MB, Gurnett CA (2009) Update on clubfoot: etiology and treatment. Clin Orthop Relat Res 467(5):1146-1153

4. Ponseti IV, Campos J (1972) The classic: observations on pathogenesis and treatment of congenital clubfoot. Clin Orthop Relat Res 467(5):1124-1132
5. Bor N, Coplan JA, Herzenberg JE (2009) Ponseti treatment for idiopathic clubfoot: minimum 5-year followup. Clin Orthop Relat Res 467(5):1263-1270

6. Ponseti IV, Brand RA (2009) Clubfoot: etiology and treatment. Clin Orthop Relat Res 467(5):1121-1123

7. Turra S, Pavanini G, Volpe A (1971) Surgical correction of the resistant club foot. One-stage posteromedial release with internal fixation: a preliminary report. J Bone Joint Surg Am 53(3):477-497

8. Zwick EB, Kraus T, Maizen C, Steinwender G, Linhart WE (2009) Comparison of Ponseti versus surgical treatment for idiopathic clubfoot: a short-term preliminary report. Clin Orthop Relat Res 467(10):2668-2676

9. Napiontek M (trans) (2007) Clubfoot: Ponseti management, 2nd edn. Global-HELP, Seattle. www.global-help.org

10. Ponseti IV (1996) Congenital clubfoot. Fundamentals of treatment. Oxford University Press, New York

11. Pirani S, Naddumba E, Mathias R, Konde-Lule J, Penny JN, Beyeza T, Mbonye B, Amone J, Franceschi F (2009) Towards effective Ponseti clubfoot care: the Uganda sustainable clubfoot care project. Clin Orthop Relat Res 467(5):1154-1163

12. Segev E, Keret D, Lokiec F, Yavor A, Wientroub S, Ezra E, Hayek S (2005) Early experience with the Ponseti method for the treatment of congenital idiopathic clubfoot. Isr Med Assoc J 7(5):307-310

13. Chen RC, Gordon JE, Luhmann SJ, Schoenecker PL, Dobbs MB (2007) A new dynamic foot abduction orthosis for clubfoot treatment. J Pediatr Orthop 27(5):522-528

14. Haft GF, Walker CG, Crawford HA (2007) Early clubfoot recurrence after use of the Ponseti method in a New Zealand population. J Bone Joint Surg Am 89(3):487-493

15. Boehm S, Limpaphayom N, Alaee F, Sinclair MF, Dobbs MB (2008) Early results of the Ponseti method for the treatment of clubfoot in distal arthrogryposis. J Bone Joint Surg Am 90(7):1501-1507

16. Alves C, Escalda C, Fernandes P, Tavares D, Neves MC (2009) Ponseti method: does age at the beginning of treatment make a difference? Clin Orthop Relat Res 467(5):1271-1277

17. Spiegel DA, Shrestha OP, Sitoula P, Rajbhandary T, Bijukachhe B, Banskota AK (2009) Ponseti method for untreated idiopathic clubfeet in Nepalese patients from 1 to 6 years of age. Clin Orthop Relat Res 467(5):1164-1170

18. Eberhardt O, Schelling K, Parsch K, Wirth T (2006) Treatment of congenital clubfoot with the Ponseti method. Z Orthop Ihre Grenzgeb 144(5):497-501 